\title{
Le traitement parodontal en omnipratique
}

\section{Jean-Pierre Ouhayoun}

Publisher: Quintessence International

Language: French

ISBN: 978-2-912550-92-7

Edition: 1/e

Publish Year: 2012

Pages: 192

Price: $151.00 €$

Dr. Jean-Pierre Ouhayoun launches the book "Periodontal Treatment in General Practice" at a time when implantology seems to monopolize all the requests for training and when putting an implant appeared to some as a universal therapeutic tool for many reasons: - many practitioners being ignorant of the influence of periodontitis on the durability of implants; also - ignorance of the effectiveness of periodontal therapeutics to preserve the teeth in patients with periodontitis for much longer periods than for implants.

Periodontitis, Elements of diagnosis, Indications and application of non-surgical treatments, Role of occlusion and contention, Surgical treatments and finally Implantology are the chapters of this book essential for any

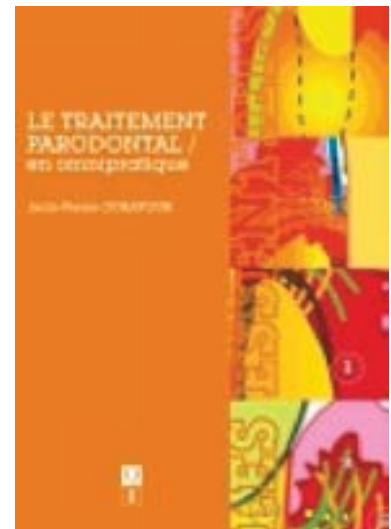

practitioner concerned with the periodontal health of his patients. The book has 192 pages and is generously and eloquently illustrated by 423 figures.

Dr. Jean-Pierre Ouhayoun's book presents his 30 years of experience as a clinician assuming constant monitoring with the caution of scientific literature. This book provides answers to the important clinical situations encountered in the everyday practice of periodontitis as an update of knowledge and clinical practice essential for all modern practitioners.
Marian-Vladimir Constantinescu $\mathrm{DDS}, \mathrm{PhD}$ Department of Prosthetic Dentistry "Carol Davila" University of Medicine and Pharmacy Bucharest, Romania Email:

dr.vadimir.constantinescu@gmail.com 